\title{
POSTPNEUMONECTOMY EMPYEMA TREATMENT - STATE OF THE ART
}

\author{
Danail Petrov, Georgi Yankov \\ Department of Thoracic Surgery, St. Sofia University Hospital for Pulmonary Diseases, \\ Medical University of Sofia, Sofia
}

\begin{abstract}
A thorough review of all the methods for postpneumonectomy empyema treatment is presented. Surgical principles of treatment include evacuation of pus and debridement of the infected tissue combined with obliteration, marsupialization, or opening of the infected cavity. The indications, advantages and disadvantages of the different surgical procedures are analyzed. Special attention is paid to the accelerated methods and video-assisted thoracoscopic debridement in the management in this severe complication associated with bronchopleural fistula. Postpneumonectomy empyema treatment as a combination of several methods should be individually tailored. Accelerated Weder procedure is an effective method in postpneumonectomy empyema with or without bronchopleural fistula.
\end{abstract}

Key words: postpneumonectomy empyema, bronchopleural fistula, surgical treatment, video-assisted thoracoscopic debridement, advantages

Postpneumonectomy empyema (PPE) is a rare but severe complication with an incidence rate of $4,4 \%$ to $16 \%(9,36,49)$. Seventy-five percent of PPE occur within the first three months of pneumonectomy (38), however, it may appear even years after the procedure (46). In up to $80 \%$ of the patients, PPE is associated with bronchopleural fistula (BPF) (49). Despite usage of various therapeutic approaches and techniques during the last five decades, successful therapy remains difficult and is often associated with high mortality rate (total of $10-20 \%$ and with BPF up to $50 \%$ ), morbidity rate and prolonged hospitalization $(1,26,38)$.

PPE development is adversely affected by different factors, especially benign disease and lower diffusing capacity for carbon monoxide $\left(\mathrm{DL}_{\mathrm{CO}}\right)$

Address for correspondence:

Danail Petrov, MD, PhD, DSc, FETCS

1 N. Pavlovich Str., 1942 Sofia, Bulgaria

e-mail:danail_petrov@hotmail.com

Received: March 4, 2013

Accepted: July 30, 2013 $(\mathrm{p}=0,001)$ followed by lower forced expiratory volume $\left(\mathrm{FEV}_{1}\right)$, lower preoperative serum hemoglobin, right pneumonectomy, bronchial stump reinforcement, completion pneumonectomy, timing of chest tube removal and amount of blood transfusions (9). Other major risk factors for PPE are immunosuppression, neoadjuvant or adjuvant therapy $(12,39)$.

The incidence rate of PPE and BPF vary from 15 to $1,3 \%$. Recently, according to a large patients' cohort study, it is of $3,8 \%$ (37). A shorter length and coverage of the bronchial stump as well as early extubation may prevent the risks of BPF. Bronchial stump closure with staples has a protective effect against BPF compared with suture closure $(9,14)$.

PPE affects a large size of the infected noncollapsible chest cavity that is filled with pus and covered by poorly vascularized infected tissue. There are diverse sources of infection of the postpneumonectomy cavity. An incidental infection of the pleural cavity may ensue during the operation as result of spilling of secretions from the respiratory tree or after operation because of a leaking bronchial stump into the postpneumonectomy cavity (23). 
An increase of mixed infections with two or three bacterial strains and an increase of Gram (-) bacteria including Pseudomonas aeruginosa has been observed (22). A similar observation has been published (29), however, cultures are often negative because of the antibiotic treatment. Analysis of bacterial culture allow to make an appropriate decision of changing the antibiotic preliminarily used in perioperative prophylaxis.

Surgical principles of treatment for infected spaces are well-known and include evacuation of pus and debridement of the infected tissue combined with obliteration, marsupialization, or opening of the infected cavity (36).

Emergency tube thoracostomy drainage should be the first step in the acute phase of the empyema. Patients should be instructed to lie with their operative side until the empyema could be drained to prevent spillage into the remaining lung. Bronchoscopy is then performed to confirm or rule out BPF. Most cases of operative mortality are secondary to respiratory failure from pulmonary infection that may have occurred from spillage of the empyema across the BPF into the contralateral lung (49).

Sterilization (debridement and closure of present BPF) and obliteration of pleural cavity (antibiotic plombage, muscle and omental pedicle flaps or thoracoplasty) follow the first step.

There is no universally appropriate treatment and that is why management depends upon the PPE stage, BPF presence and patient's general condition (36). In the absence of BPF, aggressive surgery is questioned because of its high morbidity rate and because it does not totally prevent recurrences (9).

Pleural cavity drainage alone is considered a palliative procedure (49). As a definitive treatment it includes irrigation by additional apical drain and endoscopic closure of small bronchial fistulas by fibrine glue if needed. The shortcomings of the method are prolonged treatment, discomfort caused by the intrapleural drain, uncertain cavity obliteration and chest deformity. Nevertheless, eight patients with PPE are successfully treated by continuous soft tube thoracostomy, intrapleural fibrinolysis, and antibiotics (6).

In 1963, a two-stage 'Clagett' procedure has been introduced (7). It consists of i) open pleural drainage (open window thoracostomy, OWT) with pleural space cleansing and, eventually, obliteration by daily dressing changes through the thoracostomy for 4-6 weeks followed by ii) obliteration of the pleural cavity with debridement antibiotic solutions (DABs) at the time of chest wall closure. The procedure has been successful in $88 \%$ of the cases $(n=14)$. However, it has resulted in prolonged hospitalization and significant morbidity rate. Usually, failure is due to persistent or recurrent $\mathrm{BPF}$ (41). In order to address these failures, 'Clagett' procedure is modified with initial bronchial stump reinforcement and reduction of pleural cavity size by transposition of well-vascularized extrathoracic muscle as an intermediate step before obliteration of the pleural cavity with antibiotic solution (29). The success of this modification (n28 ) is $83,9 \%$. However, surgical reinterventions are numerous and hospitalization time is too long (29).

Mayo Clinic experience of 84 patients shows that initial chest closure before hospital discharge fails in 19\% while after a second 'Clagett' procedure, chest walls are successfully closed in $88 \%$ of the patients (50). Eight patients (9,5\% of the cases) should live with a permanent thoracic wall defect. BPF healing is achieved in all the 55 patients. However, the recurrence rate after the first attempt is $18 \%$, and that after the second attempt $5 \%$ only. Perioperative mortality rates is $7,1 \%$. Late PPE onset and immediate thoracostomy creation (24) as well as age under 65 years (50) are significant predictors of OWT closure. As the process of pleural space obliteration after OWT alone may take up to two years (48), the need for further surgery to obliterate the pleural space are suggested $(35,50)$. Different extrathoracic muscles or omental transposition can be applied to obliterate the pleural space. Both omentum and muscle flaps may play an important role in infection control. Furthermore, they stimulate neoangiogenesis of ischemic bronchial stumps. Using intrathoracic muscular or omental transposition one should kept in mind that no residual space should be left and that a sufficient number of flaps must be available to fill any space. Extrathoracic muscle flap advantages are reliable blood supply, ability to reach almost any part of the pleural space, and sufficient volume to fill the cavity $(25,29)$. Their application may, however, lead to functional impairment and thus they are contraindi- 
cated in debilitated patients, following radiotherapy and posterolateral thoracotomy.

Cavity obliteration should be carried out at least three months after an operation for benign disease (24). The arguments against operative OWT closure within two years of PPE in lung cancer patients are the acceptable probability of spontaneous resolution and the risk of recurrent disease (34). In this setting, waiting no less than six months between performing and closing OWT is recommended (13).

Omental pedical flap maintains a rich blood supply and lymph circulation, accelerates vascularization due to angiogenic factors, promotes drug transfer in the peripheral blood to affected areas, exerts potent anti-inflammatory and self-cleaning effects and has a sufficient volume. The procedure is minimally invasive and simple (37). Omentoplasty could be applied in poor-risk patients, in patients with history of radiotherapy and posterolateral thoracotomy, and, especially, in patients with BPF (27).

$\mathrm{BPF}$ closure is of paramount importance in PPE treatment. Different techniques depend on the type and size of the insufficiency. Endoscopic treatment of $\mathrm{BPF}$ less than $3 \mathrm{~mm}$ with various glues and sclerosing agents is a minimally invasive procedure that plays an essential role, particularly in high risk patients $(21,28,44,45)$.

The stump can be accessed via the same pleural cavity through the contralateral pleural cavity in case of left stump fistula (31) and by means of transmediastinal video-assisted thoracoscopy (VATS) application (4). The advantages of transsternal transpericardial closure of BPF or Abruzzini technique (2) are the following: avoidance of areas of infection, scarring in previous surgical fields, devascularized bronchus, and cosmetic and functional deformities of the thorax because of thoracoplasty. This technique is an alternative in the management of persistent fistula after repair by other techniques (43). The disadvantage of this method is that the residual empyema space is not dealt with at the same time with BPF closure and additional surgical procedures are needed. Several authors performed carinal resection using the transsternal approach in cases with a short, less than $5 \mathrm{~mm}$ bronchial stump $(8,23,31,33,42)$. A miniinvasive Abruzzini-like tech- nique using three simultaneous approaches such as cervical videomediastinoscopy, right anterior mediastinotomy and parasternal thoracoscopic port has been developed (40).

Prolonged and very expensive treatment represents the disadvantages of the older procedures for PPE treatment.

In patients with early PPE associated with BPF, a $100 \%$ success rate with shorter hospitalization and decreased morbidity are reported (41). Their 'Clagett' procedure modification is based on emergency tube drainage followed by thoracotomy, debridement, bronchial stump resuture, and immediate chest cavity closure. Postoperative pleural irrigation and space obliteration by antibiotic solution constitute the final part of the treatment. This approach should, however, be considered only in a highly selected subset of patients.

Accelerated Weder method may be considered an advancement of 'Clagett' procedure. It leads to a high success rate of $97,3 \%$ with a mean postoperative hospital stay of $17-18$ days $(36,37)$. The therapy consists of repeated open surgical debridement of the pleural cavityafter achievement of general anesthesia, a negative pressure wound therapy (11) of the temporarily closed chest cavity filled with povidoneiodine-soaked towels, and continuous suction and systemic antimicrobial therapy. If present, BPF are closed and reinforced either with a muscle flap, or with the omentum. Finally, the pleural space is filled with an antibiotic solution and definitively closed.

The procedure is repeated every 48 hours and, usually, a mean amount of 3,5 procedures is enough until the chest cavity is macroscopically clean.

A video-assisted modification of Weder procedure is recently introduced in three patients (32). The previous thoracotomy is not open. In cases with a previous chest tube drainge, a wide excision of the surrounding soft tissues such as skin and muscles is carried out and the prepared $4-\mathrm{cm}$ thoracotomy is applied for inserting the telescope and the working instruments into the cavity. In cases without such a drainage, a small $4 \mathrm{~cm}$ muscle-sparing axillar thoracotomy is performed. A radical pleural cavity VATS debridement (VATSD) is carried out followed by irrigation with diluted povidone-iodine solution (1:10). At the end of every surgical intervention, but 
before the definitive closure, the pleural cavity is packed with dressings soaked with povidone-iodine solution, carefully avoiding the mediastinal shift through overstuffing the thoracic cavity. No intrathoracic drain (less pain and mobile patient) is put and pleural cavity is carefully closed with interrupting suturing of the soft tissues (32). Every 48 hours, the antiseptic packings are changed and the surgical debridement is repeated in the operating theatre until the chest cavity is macroscopically clean. Finally, the pleural space is obliterated with an antibiotic solution and the minithoracotomy is definitively closed watertight. General endotracheal anesthesia is given for the first surgical session of the procedures based on the assumption that more extensive surgery might be required. The anesthesia for the remaining sessions and for postoperative pain relief is high thoracic epidural anesthesia via catheter with preserved self-ventilation. PPE is successfully treated in all the patients during three sessions needed with a mean hospital stay of 10,3 days followed by excellent longterm functional and cosmetic results.

Limited experience with VATSD in PPE management may be due to the fear of using VATS for a severe and potentially lethal complication as well as of overlooking the infected tissues in the regions that are difficult to reach with the thoracoscope (19). However, there is no evidence that success relies on complete debridement of all the infected tissues. If VATS does not accomplish as thorough a pleural cleaning as does thoracotomy, it is often successful because the bacterial load and inflammatory exudates are reduced below a critical level allowing the pleural space to recover (47).

In 9 patients, infected materials are cleaned by videothoracoscopy and subsequent postoperative antibiotic irrigation according to culture sensitivity via single chest tube drainage twice a day (18). Empyema is considered eradicated, if three consecutivve cultures show no bacterial growth with a mean hospital stay of 29 days. VATSD is applied, too (15), however, without any postoperative irrigation. In the case of persistent infectious symptoms (27\% recurrence rate), thoracoscopy is not repeated and OWT is performed. Treatment begins with pleural cavity antibiotic irrigation for 10 days through two chest tubes twice a day (5). Pleural instillation of $250000 \mathrm{U}$ streptokinase is done two hours prior to procedure. Then VATSD is carried out under general anaesthesia and tube drainage is placed in the chest cavity. This protocol provides satisfactory results in terms of hospital stay and number of sepsis recurrences. Three PPE patients are treated with repeated VATSD and intermittent lavage with polyvinyl pyrolidine-iodine solution and streptocinase/streptodornase (10). Three to seven thoracoscopies under general anaesthesia are required to sterilize the pleural cavity. After a median follow-up of 14 months all these patients feel well and present without any evidence of infection.

A repeated VATSD and lavage with povidoneiodine solution are successfully carried out every 48 hours in four patients via 2 ports, too, however, only the first VATSD is done under general anaesthesia (32). The next VATS procedures are performed using epidural analgesia at the T6-8 interspace. Between the procedures the pleural cavity is filled with povidone-iodine solution (1:10), without any intrapleural tube drainage. The advantages of this VATSD protocol (32) are the following: restoration of aseptic PPE cavity in $100 \%$ of the patients, no chest tube drainage-less pain, mobile patient, only the first session is under general anaesthesia, good quality of life and functional results, short hospital stay and moderate costs, low morbidity rate and possibility to perform further aggressive treatment in case of failure. The relative disadvantages are the following: three VATSD within five days and inadequate reimburcement by the health insurance funds as one procedure for hospitalization is paid only.

Several authors emphasize that limited thoracoplasty is an excellent therapeutic option for treating PPE, avoiding multiple operative procedures and the psychological drawbacks of prolonged hospitalization or of definitive open drainage $(16,17,20)$. About $75 \%$ of the patients start to work again (30).

Thoracopleuroplasty as described by Andrews (3) allows a good control of infection with complete evacuation of the products of empyema under direct vision, an immediate closure of any bronchial fistula, an one stage-procedure, and a rapid and most often simple postoperative recovery (19). This surgical procedure could be at least an alternative method to open thoracostomy always when a secondary closure 
seems uncertain, or is used in case of failure of other treatment modalities. These results and the quality of life after this thoracopleuroplasty should support the rediscovery of this time-honoured procedure in properly selected patients (19).

In conclusion, PPE treatment usually as a combination of several methods should be individually tailored for every patient. Accelerated Weder procedure is an effective method in PPE with or without BPF. Extrathoracic muscle myoplasty is an excellent method for obliteration of PPE cavity with BPF. Due to its detersion capacity and sufficient volume omentoplasty is effective and safe procedure in selected cases of PPE with BPF, too. VATSD and VATS modification of Weder procedure can manage most PPE patients with minor BPF successfully treated bronchoscopically or without any BPF. They do not preclude more aggressive surgical treatment in case of failure or relapse.

\section{REFERENCES}

1. Abbas, Ael-S, C. Deschamps. Postpneumonectomy empyema.- Curr. Opin. Pulm. Med., 8, 2002, No 4, 327-333.

2. Abruzzini, P. Trattamento chirurgico delle fistole del bronco principale consecutive a pneumonectomia per tubercolosi.- Chirur. Torac., 14, 1961, 165-171.

3. Andrews, N. C. Thoraco-mediastinal plication: a surgical technique for chronic empyema.- $J$. Thorac. Surg., 41, 1961, 809-816.

4. Azorin, J. F., M. P. Francisci, B. Tremblay, P. Larmignat, D. Carvaillo. Closure of a postpneumonectomia main bronchus fistula using video-assisted mediastinal surgery.- Chest, 109, 1996, No 4, 1097-1098.

5. Bagan, P., F. Boissier, P. Berna, A. Badia, F. Le Pimpec-Barthes, R. Souilamas, et al. Postpneumonectomy empyema treated with a combination of antibiotic irrigation followed by videothoracoscopic debridement.- J. Thorac. Cardiovasc. Surg., 132, 2006, No 3, 708-710.

6. Ben-Nun, A., M. Soudack, L. A. Best. Nonsurgical treatment for post pneumonectomy empyema.- Interact. Cardiovasc. Thorac. Surg., 2, 2003, No 4, 616-619.
7. Clagett, O. T., J. E. Geraci. A procedure for the management of postpneumonectomy empyema.- $J$. Thorac. Cardiovasc. Surg., 45, 1963, 141-145.

8. de la Riviere, A. B., J. J. Defauw, P. J. Knaepen, H. A. van Swieten, R. C. Vanderschueren, J. M. van den Bosch. Transsternal closure of bronchopleural fistula after pneumonectomy.- Ann. Thorac. Surg., 64, 1997, No 4, 954-957; discussion, 958-959.

9. Deschamps, C., C. Pairolero, M. S. Allen, V. F. Trastek. Management of postpneumonectomy empyema and bronchopleural fistula.- Chest Surg. Clin. N. Am., 6, 1996, No 3, 519-527.

10. Ernst, M., C. Nies. Thoracoscopic therapy of pleural empyema after pneumonectomy.- Chirurg, 70, 1999, No 12, 1480-1483 (in German).

11. Field, F. K., M. D. Kerstein. Overview of wound healing in a moist environment.- Am. J. Surg., 167, 1994, No 1A, S2-S6.

12. Frytak, S., R. E. Lee, P. C. Pairolero, P. G. Arnold, J. N. Shaw. Necrotic lung and bronchopleural fistula as complications of therapy in lung cancer.- Cancer Invest., 6, 1988, No 2, 139-143.

13. García-Yuste, M., G. Ramos, J. L. Duque, F. Heras, M. Castanedo, L. J. Cerezal, et al. Open-window thoracostomy and thoracomyoplasty to manage chronic pleural empyema.- Ann. Thorac. Surg., 65, 1998, No 3, 818-822.

14. Gharagozloo, F., M. Margolis, M. Facktor, B. Tempesta, F. Najam. Postpneumonectomy and postlobectomy empyema.- Thorac. Surg. Clin., 16, 2006, No 3, 215-222.

15. Gossot, D., J. B. Stern, D. Galetta, D. Debrosse, P. Philippe Girard, R. Caliandro, et al. Thoracoscopic management of postpneumonectomy empyema.Ann. Thorac. Surg., 78, 2004, No 1, 273-276.

16. Grégoire, R., J. Deslauriers, M. Beaulieu, M. Pireaux. Thoracoplasty: its forgotten role in the management of nontuberculous postpneumonectomy empyema.- Can. J. Surg., 30, 1987, No 5, 343-345.

17. Horrigan, T. P., N. J. Snow. Thoracoplasty: current application to the infected pleural space.- Ann. Thorac. Surg., 50, 1990, No 5, 695-699.

18. Hollaus, P. H., F. Lax, B. B. El-Nashef, H. H. Hauck, P. Lucciarini, N. S. Pridun. Natural history of bronchopleural fistula after pneumonectomy; a review of 96 cases.- Ann. Thorac. Surg., 63, 1997, No 5, 1391-1396, discussion, 1396-1397. 
19. Icard, P., J. P. Le Rochais, B. Rabut, S. Cazaban, B. Martel, C. Evrard. Andrews thoracoplasty as a treatment of post-pneumonectomy empyema: experience in 23 cases.- Ann. Thorac. Surg., 68, 1999, No 4, 1159-1163; discussion, p. 1164.

20. Jadczuk, E. Postpneumonectomy empyema.- Eur. J. Cardiothorac. Surg., 14, 1998, No 2, 123-126.

21. Jessen, C., P. Sharma. Use of fibrin glue in thoracic surgery.- Ann. Thorac. Surg., 39, 1985, No 6, 521-524.

22. Kacprzak, G., M. Marciniak, E. Addae-Boateng, J. Kolodziej, K. Pawelczyk. Causes and management of postpneumonectomy empyemas: our experience.- Eur. J. Cardiothorac. Surg., 26, 2004, No 3, 498-502.

23. Knaepen, P. Discussion of: Ginsberg, R. J., F. G. Pearson, J. D. Cooper, E. Spratt, J. Deslauriers, M. Goldberg, et al. Closure of chronic postpneumonectomy bronchopleural fistula using the transsternal transpericardial approach.- Ann. Thorac. Surg., 47, 1989, No 2, 234-235.

24. Massera, F., M. Robustellini, C. D. Pona, G. Rossi, A. Rizzi, G. Rocco. Predictors of successful closure of open window thoracostomy for postpneumonectomy empyema.- Ann. Thorac. Surg., 82, 2006, No 1, 288-292.

25. Miller, J. I., K. A. Mansour, F. Nahai, M. J. Jurkiewicz, C. R. Hatcher, Jr. Single-stage complete muscle flap closure of the postpneumonectomy empyema space: a new method and possible solution to a disturbing complication.- Ann. Thorac. Surg., 38, 1984, No 3, 227-231.

26. Misthos, P., S. Kakaris, E. Sepsas, K. Athanassiadi, I. Skottis. Surgical management of late postpneumonectomy bronchopleural fistula: the transsternal, transpericardial route.- Respiration, 73, 2006, No 4, 525-528.

27. Okumura, Y., S. Takeda, H. Asada, M. Inoue, N. Sawabata, H. Shiono, et al. Surgical results for chronic empyema using omental pedicled flap: long-term follow-up study.- Ann. Thorac. Surg., 79, 2005, No 6, 1857-1861.

28. Opie, J. C., C. C. Vaughn, R. A. Comp, J. M. Radford, P. Lowell, C. Finch. Endobronchial closure of a postpneumonectomy bronchopleural fistula.Ann. Thorac. Surg., 53, 1992, No 4, 686-688.

29. Pairolero, P. C., P. G. Arnold, V. F. Trastek, N. B. Meland, P. P. Kay. Postpneumonectomy empyema. The role of interthoracic muscle transposition.- J.
Thorac. Cardiovasc. Surg., 99, 1990, No 6, 958-966; discussion, 966-968.

30. Peppas, G., T. F. Molnar, K. Jeyasingham, A. B. Kirk. Thoracoplasty in the context of current surgical practice.- Ann. Thorac. Surg., 56, 1993, No 4, 903-909.

31. Perelman, M. I., G. P. Ambatjello. Transpleuraler, transsternaler und kontralateraler Zugang bei Operationen wegen Bronchialfistel nach Pneumonektomie.- Thoraxchirurgie, 18, 1970, No 1, 45-57.

32. Petrov, D., G. Yankov, S. Aleksov, Y. Yamakova. Weder's method and our minimal-invasive videoassisted modification for accelerated treatment of postpnemonectomy empyema.- Khirurgiya (Sofia), 67, 2011, No 3, 62-65 (in Bulgarian).

33. Porhanov, V., I. Poliakov, V. Kononenko, A. Selvaschuk, V. Bodnya, S. Semendiaev, et al. Surgical treatment of 'short stump' bronchial fistula.- Eur. J. Cardiothorac. Surg., 17, 2000, No 1, 2-7.

34. Postmus, P. E., J. M. Kerstjens, W. J. deBoer, J. N. Homan van der Heide, G. H. Koeter. Treatment of postpneumonectomy pleural empyema by openwindow thoracostomy.- Eur. Resp. J., 2, 1989, No 9, 853-855.

35. Regnard, J. F., M. Alifano, P. Puyo, E. Fares, P. Magdeleinat, P. Levasseur. Open window thoracostomy followed by intrathoracic flap transposition in the treatment of empyema complicating pulmonary resection.- J. Thorac. Cardiovasc. Surg., 120, 2000, No 2, 270-275.

36. Schneiter, D., P. Cassina, S. Korom, I. Inci, M. AlAbdullatief, A. Dutly, et al. Accelerated treatment for early and late postpneumonectomy empyema.Ann. Thorac. Surg., 72, 2001, No 5, 1668-1672.

37. Schneiter, D., T. Grodzki, D. Lardinois, P. B. Kestenholz, J. Wojcik, B. Kubisa, et al. Accelerated treatment of postpneumonectomy empyema: A binational long-term study.- J. Thorac. Cardiovasc. Surg., 136, 2008, No 1, 179-185.

38. Shamji, F. M., R. J. Ginsberg, J. D. Cooper, E. H. Spratt, M. Goldberg, P. F. Waters, et al. Open window thoracostomy in the management of postpneumonectomy empyema with or without bronchopleural fistula.- J. Thorac. Cardiovasc. Surg., 86, 1983, No 6, 818-822.

39. Sonobe, M., M. Nakagawa, M. Ichinose, N. Ikegami, M. Nagasawa, T. Shindo. Analysis of risk factors in bronchopleural fistula after pulmonary 
resection for primary lung cancer.- Eur. J. Cardiothorac. Surg., 118, 2000, No 5, 519-523.

40. Spaggiari, L., P. Carbognni, P. Solli, M. Rusca. Video-assisted modified Abruzzini technique for bronchial fistula repair.- Ann. Thorac. Surg., 65, 1998, No 4, 1198-1200.

41. Stafford, E. G., O. T. Clagett. Postpneumonectomy empyema: neomycin instillation and definitive closure.- J. Thorac. Cardiovasc. Surg., 63, 1972, No $5,771-775$.

42. Stamatis, G., G. Martini, L. Freitag, M. Wencker, D. Greschuchna. Transsternal transpericardial operations in the treatment of bronchopleural fistulas after pneumonectomy.- Eur. J. Cardiothorac. Surg., 10, 1996, No 2, 83-86.

43. Topcuoglu, M. S., C. Kayhan, T. Ulus. Transsternal transpericardial approach for the repair of bronchopleural fistula with empyema.- Ann. Thorac. Surg., 69, 2000, No 2, 394-397.

44. Torre, M., E. Quaini, M. Ravini, F. P. Nerli, M. Maioli. 1987: Endoscopic gluing of bronchopleural fistula. Updated in 1994.- Ann. Thorac. Surg., 58, 1994, No 3, 901-902.
45. Tsunezuka, Y., H. Sato, T. Tsukioka, C. Hiranuma. A new instrument for endoscopic gluing for bronchopleural fistulae.- Ann. Thorac. Surg., 68, 1999, No 3, 1088-1089.

46. Wain, J. C. Management of late postpneumonectomy empyema and bronchopleural fistula.- Chest Surg. Clin. N. Am., 6, 1996, No 3, 529-541.

47. Wait, M., S. Sharma, J. Hohn, A. Dal Nogare. A randomized trial of empyema therapy.- Chest, 111, 1997, No 6, 1548-1551.

48. Weissberg, D. Empyema and bronchopleural fistula. Experience with open window thoracostomy.- Chest, 82, 1982, No 4, 447-450.

49. Wong, P. S., P. Goldstraw. Post-pneumonectomy empyema.- Eur. J. Cardiothorac. Surg., 8, 1994, No 7, 345-349; discussion, 349-350.

50. Zaheer, S., M. S. Allen, S. D. Cassivi, F. C. Nichols, $3^{\text {rd }}$, C. H. Johnson, C. Deschamps, et al. Postpneumonectomy empyema: results after the Clagett procedure.- Ann. Thorac. Surg., 82, 2006, No 1, 279-286, discussion, 286-287. 